\title{
Commentary \\ Understanding Vulnerability in Girls and Young Women with High-Functioning Autism Spectrum Disorder
}

\author{
Susan Jane Bradley
}

check for updates

Citation: Bradley, S.J. Understanding Vulnerability in Girls and Young Women with High-Functioning Autism Spectrum Disorder. Women 2022, 2, 64-67. https://doi.org/ 10.3390 /women 2010007

Academic Editors: Mary V. Seeman and Domenico De Berardis

Received: 22 September 2021

Accepted: 23 February 2022

Published: 27 February 2022

Publisher's Note: MDPI stays neutral with regard to jurisdictional claims in published maps and institutional affiliations.

Copyright: (c) 2022 by the author. Licensee MDPI, Basel, Switzerland. This article is an open access article distributed under the terms and conditions of the Creative Commons Attribution (CC BY) license (https:// creativecommons.org/licenses/by/ $4.0 /)$.
Professor Emerita Department of Psychiatry, University of Toronto, Toronto, ON M5S 1A1, Canada; susan.bradley589@gmail.com

\begin{abstract}
There is a population of young women with autism spectrum disorder (ASD) who function relatively well so that their disorder is not easily recognized. If their difficulties with emotion regulation in childhood continue into adolescence they are vulnerable to the development of a number of mental disorders, treatment of which can be difficult if the presence of ASD is not understood. In this commentary, I use the example of gender dysphoria to illustrate the issues.
\end{abstract}

Keywords: autism spectrum disorder; gender dysphoria; adolescence

As a Child Psychiatrist who founded the first academic clinic for children and adolescents with Gender Identity Disorder (GID) in Canada at the then Clarke Institute of Psychiatry in 1975, I have become very concerned about the seeming lack of psychological understanding by care providers of young teens presenting with this disorder. Our clinic was led by Dr. Ken Zucker after I moved to the Hospital for Sick Children, where I was Psychiatrist-in-Chief and Head of Child and Adolescent Psychiatry for the University of Toronto for ten years. Under Dr. Zucker's leadership, the clinic became one of the leading academic programs for these disorders; it became well known and respected by clinicians and scientists around the world because of the numerous authoritative publications that arose from our work. Our book [1], published in 1995, was considered the foremost guide in this area for many years. However, a few years ago, the clinic was shut down because of political pressure.

The pressure came from activist groups that disagreed with our observations about the malleability of GID. A recent report [2] by one of our former students indicates that the majority of the children seen in the clinic, once grown up, relinquished their desire to transition to the opposite sex and instead, as adults, mainly self-identified as lesbian or gay. This finding has been confirmed by other groups who have longitudinally followed young children with GID, both treated and untreated.

Given such findings, current affirmative medical approaches that offer hormonal and surgical treatments to youth when they first present with Recent Onset Gender Dysphoria (ROGD) [3] is a matter of grave concern to practitioners experienced in this area. ROGD, which afflicts mainly young women who appear to be caught up in a cult-like movement and encouraged to radically change their bodies, has effectively shut down the voices of those who counsel a period of waiting and deeper understanding before embarking on a journey that may be profoundly regretted. This commentary is aimed at mental health professionals, including pediatricians, who are consulted by parents when their daughters express concern about their gender identity. Clearly the views expressed in this commentary are not shared by those advocating for the Affirmative Medical approach.

Early on in our clinic's experience seeing children and teens with GID, we were less aware than we are today of high-functioning autism spectrum disorder (ASD). Despite searching for biological causes for GID and finding nothing specific, (for a more thorough review see Debra Soh's book [4]), we became more interested in the underlying issues that increase vulnerability in this area. Recently, and particularly with the emerging pandemic 
of ROGD, we and others have recognized that many of the young women we treated suffered from high-functioning ASD [5-7]. This became clearer for me when I worked as a consultant to a variety of Children's Mental Health Centers after leaving Sickkids. Most of the girls I saw had not been previously diagnosed with ASD because they melded into the mainstream more easily than boys with ASD. They presented with anxiety, depression suicidal thinking, self-harm behaviors, eating disorders and gender dysphoria. Before my retirement, one of the larger agencies estimated that, over a ten year period, I had seen more than 500 children and teens with undiagnosed ASD. This reflects a possible increasing prevalence of ASD [8] but it also reflects my increasing awareness of this disorder as a risk factor for a variety of psychopathologies in young women.

Clinically, the parents of these girls regularly speak of their daughters' difficulties regulating their feelings. In the younger children, the presentation often manifests in "meltdowns," but, in the teens, it more commonly presents as anxiety and depression. In my experience, neither the anxiety nor depression is typical for those diagnoses, often coming and going in reaction to perceived stresses. Suicidal thinking is also commonly seen but it is often fleeting and again related to perceived slights or rejections. Clinicians working with these youth often report a lack of success with such approaches as CBT and they sense that these youth have trouble fully understanding tasks such as analyzing their feelings and related triggers and putting into words how they think about their thoughts. The patients' difficulty with theory of mind is seen as the underlying cause of the therapeutic impasse. Furthermore, they are described as exhibiting a rigid style of thinking that makes it hard for them to change their thinking, especially if they believe they are right/have found a solution to their distress.

Developmentally, these young girls have typically had trouble making friends and often feel rejected and left out of peer groups. Their interests are often less mature than that of their peers and they do not really understand why peers are not very interested in them as friends. Their self-esteem is usually impacted by this rejection, which becomes particularly acute as they enter adolescence when peer groups become socially very important. They often think of themselves as different in some way that they find hard to explain. Crushes on popular girls are not uncommon in many teens, but, not knowing this, the emotions that are aroused may make these young women feel increasingly "weird". In the current culture of politically correct affirmation of gender dysphoria, it translates into meaning that you are "trans", which, for many young women, is less anxiety-provoking than being lesbian. Most have not had a prior history of gender dysphoria but their belief that they have found an answer to their distress, along with their style of rigid thinking, makes it hard to self-reflect in terms of other possible explanations for their feelings. Being welcomed by "trans" advocates acts as the external push. Young women who have gone through this and have subsequently de-transitioned have been very helpful in that they have gained an understanding of their experience and have realized that transitioning did not relieve their original feelings. Most have reported accepting that they are lesbian, especially when they enter into a relationship in which they are accepted for who they are.

Although "trans" advocates argue that they were "born that way," there is little evidence of a biological factor determining one's gender identity [9]. As stated earlier, studies following up young children with gender identity disorders with or without therapeutic support find that the majority have relinquished their desire to transition and describe themselves as mainly lesbian or gay. However, we do know that those young women who begin puberty blockers are more likely to continue to seek cross-sex hormones and surgery than do those who are not so exposed [10-12]. These findings have raised issues that, despite our best intentions regarding help for these young women, often in the belief that we are preventing suicide, may reinforce their belief that they should proceed to transition as opposed to buying time for them to consider other options.

Although I am using the example of gender dysphoria here as an example of misdiagnosis of young women with high-functioning ASD, I believe that the distress of these young women can be mislabeled in many different ways. Because they are high functioning, their 
ASD may not be apparent until they are older. They clearly suffer from high levels of anxiety and depression, but also from eating disorders and body dysphoria. Understanding the developmental origins and style of thinking that may make these young women more resistant to regular psychiatric interventions and, therefore, more vulnerable, is very important to their effective management. Some may question if these young women should also be diagnosed as having Borderline Personality Disorder. This is an ongoing issue in the literature but I believe that evidence of earlier ASD features should suggest that ASD is the simpler and more logical diagnosis.

As the most parsimonious way of understanding difficulties in self-regulation in ASD I have adopted Steve Porges' theory [13] of vagal nerve dysfunction in ASD as this theory helps to explain the symptoms of "meltdowns" in younger children but also the difficulty in managing stress during the teenage years. Essentially, Porges posits that their parasympathetic nervous system is less able to return the autonomic nervous system to normal after stress than it is in typical individuals. In his book "The PolyVagal Theory", Porges describes the intricate way in which the myelinated part of the vagus, which oversees the body's restorative functions including social engagement, works in concert with the sympathetic or mobilizing part of the autonomic nervous system to allow response to danger and recovery from the state of readiness. When vagal tone is low or fails to respond adequately after a danger or a mobilizing signal, the individual has difficulty with self-regulation, feeling in a constant state of "fight or flight". It is postulated that being more constantly in this state of "fight or flight" can "wear out" their stress system as the vagal nerve connects with the other part of the stress management system, the hypothalamic pituitary adrenal axis (HPA axis). Porges has tested his theory in individuals with ASD, Borderline Personality Disorder and those who have experienced prior abuse and finds evidence for poorer vagal tone in these clinical populations. Another study using different measures has confirmed Porges' findings of autonomic dysfunction in ASD [14]. From my perspective, both understanding the feelings that make these young women vulnerable but also the physiology that may make it harder for them to use standard therapy or learn to regulate their feelings is crucial to effectively help them manage their distress.

Clearly, this population does not have access to evidence-based treatments that are specific to their problems with emotion regulation (ER). Mazefsky [15] provides a very good overview of factors both general and specific to ER in ASD and makes suggestions for research that may enhance efficacy of treatment interventions in ASD. The results, to date, using modified CBT for ASD, are promising but not yet conclusive [16]. Although vagal nerve stimulation appears possibly helpful it has not yet been adequately tested. This group of young people will remain vulnerable until we have evidence-based treatments and so I welcome this opportunity to encourage readers to think of this target population when designing future research programs.

Funding: This research received no external funding.

Institutional Review Board Statement: Not applicable.

Informed Consent Statement: Not applicable.

Data Availability Statement: Not applicable.

Conflicts of Interest: The authors declare no conflict of interest.

\section{References}

1. Zucker, K.; Bradley, S. Gender Identity Disorder and Psychosexual Problems in Children and Adolescents; Guilford: New York, NY, USA, 1995.

2. Singh, D.; Bradley, S.J.; Zucker, K.J. A Follow-Up Study of Boys with Gender Identity Disorder. Front. Psychiatry 2021, $12,12$. [CrossRef] [PubMed]

3. Littman, L. Rapid-onset gender dysphoria in adolescents and young adults: A study of parental reports. PLoS ONE 2018, 13, e0202330. [CrossRef] [PubMed]

4. Soh, D. The End of Gender; Threshold Editions: Toronto, ON, Canada, 2020. 
5. $\quad$ van der Miesen, A.; de Vries, A.; Steensma, T.; Hartman, C. Autistic symptoms in children and adolescents with Gender Dysphoria J. Autism Dev. Disord. 2018, 48, 1537-1548. [CrossRef] [PubMed]

6. Nabbijohn, A.N.; Van Der Miesen, A.I.R.; Santarossa, A.; Peragine, D.; De Vries, A.L.C.; Popma, A.; Lai, M.-C.; Vanderlaan, D.P. Gender Variance and the Autism Spectrum: An Examination of Children Ages 6-12 Years. J. Autism Dev. Disord. 2018, 49, 1570-1585. [CrossRef] [PubMed]

7. Warrier, V.; Greenberg, D.M.; Weir, E.; Buckingham, C.; Smith, P.; Lai, M.-C.; Allison, C.; Baron-Cohen, S. Elevated rates of autism, other neurodevelopmental and psychiatric diagnoses, and autistic traits in transgender and gender-Diverse individuals. Nat. Commun. 2021, 11, 3959. [CrossRef] [PubMed]

8. Sasayama, D.; Kuge, R.; Toibana, Y.; Honda, H. Trends in Autism Spectrum Disorder Diagnoses in Japan, 2009 to 2019. JAMA Netw. Open 2021, 4, e219234. [CrossRef] [PubMed]

9. $\quad$ Skorska, M.; Chavez, S.; Devenyi, G.; Patel, R.; Thurston, L.; Lai, M.-C.; Zucker, K.; Chakravarty, M.; Lobaugh, N.; Vanderlaan, D. A multi-modal MRI analysis of cortical structure in relation to gender dysphoria, sexual orientation, and age in adolescents. $J$. Clin. Med. 2021, 10, 345. [CrossRef] [PubMed]

10. de Vries, A.; Steensma, T.; Doreleijers, T.; Cohen-Kettenis, P. Puberty suppression in adolescents with gender identity disorder: A prospective follow-up study. J. Sex. Med. 2011, 8, 2276-2283. [CrossRef] [PubMed]

11. Carmichael, P.; Butler, G.; Masic, U.; Cole, T.; De Stavola, B.; Davidson, S.; Skageberg, E.M.; Khadr, S.; Viner, R. Short-term outcomes of pubertal suppression in a selected cohort of 12 to 15 year old young people with persistent gender dysphoria in the UK. PLoS ONE 2021, 16, e0243894. [CrossRef] [PubMed]

12. Brik, T.; Vrouenraets, L.J.J.J.; De Vries, M.C.; Hannema, S.E. Trajectories of Adolescents Treated with Gonadotropin-Releasing Hormone Analogues for Gender Dysphoria. Arch. Sex. Behav. 2020, 49, 2611-2618. [CrossRef] [PubMed]

13. Porges, S. The Polyvagal Theory: Neurophysiological Foundations of Emotions, Attachment, Communication and Self-Regulation; Norton: New York, NY, USA, 2011.

14. Ming, X.; Julu, P.; Brimacombe, M.; Connor, S.; Daniels, M.L. Reduced cardiac parasympathetic activity in children with autism. Brain Dev. 2005, 27, 509-516. [CrossRef] [PubMed]

15. Mazefsky, C.A.; Herrington, J.; Siegel, M.; Scarpa, A.; Maddox, B.B.; Scahill, L.; White, S. The role of emotion regulation in autism spectrum disorder. J. Am. Acad. Child Adolesc. Psychiatry 2013, 52, 679-688. [CrossRef] [PubMed]

16. Wang, X.; Zhao, J.; Huang, S.; Chen, S.; Zhou, T.; Li, Q.; Luo, X.; Hao, Y. Cognitive Behavioral Therapy for Autism Spectrum Disorders: A Systematic Review. Pediatrics 2021, 147. [CrossRef] [PubMed] 